\title{
Apresentação da Edição Temática
}

\section{Globalização e os Desafios à Segurança Internacional}

\section{Ricardo Oliveira dos Santos ${ }^{1}$}

\section{Sérgio Veloso ${ }^{2}$}

$\mathrm{Na}$ virada da década de 80 para 90 do século passado, as placas tectónicas da ordem geopolítica passaram por um gigantesco realinhamento. Com o fim da União Soviética e a dissolução da ordem bipolar, que dividia o mundo em dois projetos utópicos antagônicos e concorrentes, o planeta todo passou a ser ordenado com base na ideologia dos vencedores. A partir desse momento, emergia o que se convencionou chamar de uma ordem liberal global e o mundo passou a ser reconfigurado para se transformar em um grande mercado.

Essa virada histórica, rapidamente chamada de "globalização", é também marcada pela emergência de um campo de estudos dedicado à compreensão dos processos de transformação daquele mundo que se apresentava como uma grande novidade. $O$ século $X X$, das guerras viscerais e infinitas, havia finalmente terminado e uma nova era começava a surgir. Tudo que era sólido parecia estar na iminência de se desmanchar e a ideia da "globalização" passou a ser a epítome dessa grande transformação.

Se o século $X X$ foi o século das guerras mundiais, da ameaça comunista e de um possível cataclisma nuclear, o século XXI seria o da globalização do capitalismo como sistema socioprodutivo hegemônico. Rendidas à força inevitável dos modos de acumulação capitalista e seus aparatos tecnológicos, as relações humanas - em suas dimensões mais subjetivas e íntimas ou no que diz respeito às interações institucionais e disputas internacionais - seriam todas ajustadas e conformadas à disciplina produtiva do capital. Essa grande transformação global

\footnotetext{
1 É Coordenador Adjunto da Graduação (2017 - ) e Professor do Quadro Complementar (2015 - ) do Instituto de Relações Internacionais da Pontifícia Universidade Católica do Rio de Janeiro (IRI/PUCRio). Foi Professor Substituto do Departamento de Ciência Política da Universidade Federal do Rio de Janeiro (DCP/UFRJ) entre 2014-2016. Doutor em Economia Política Internacional pela Universidade Federal do Rio de Janeiro (PEPI/UFRJ). Possui graduação e mestrado em Relações Internacionais pela Pontifícia Universidade Católica do Rio de Janeiro (IRI/PUC-Rio). Foi Visiting Scholar do Instituto Multinacional de Estudos Americanos da New York University (2019) e Visiting Research Fellow do Departamento de Ciência Política/Watson Institute for International and Public Affairs da Brown University (2012).

2 Professor do Instituto de Relações Internacionais da Pontifícia Universidade Católica do Rio de Janeiro (IRI/PUC-Rio) e Coordenador do Programa BRICS-Urbe do BRICS Policy Center. É Doutor e Mestre em Relações Internacionais pelo IRI/PUC-Rio. Também é Mestre em Estudos Culturais pela Universidade Jagiellonian, Cracóvia, Polônia. É também Bacharel e licenciado em História pela Universidade Federal de Juiz de Fora (UFJF).
} 
das relações a partir do capitalismo foi captada e depurada no campo de estudos da globalização por autores de diversos posicionamentos teóricos e políticos. O campo é, então, marcado muito mais pela pluralidade e multiplicidade de leituras e análises divergentes do que por noções consensuais.

Em 2006, Nayef Al-Rodhan e Gérard Stoudman compilaram 114 definições distintas sobre globalização. Essa compilação, claro, é datada e não dá conta das transformações que o campo sofreu na última década, mas, de toda forma, evidencia a pluralidade e multiplicidade de leituras que ainda caracteriza o campo. Globalização é por vezes apresentado como um processo por meio do qual o mundo se converteria em um grande shopping center (Moss Kanter, 1995); como uma nova roupagem para colonização, agora reconfigurada como uma força a serviço do capital (Neeraj, 2001); ou, segundo definição compartilhada pelo Estado canadense, FMI, Banco Mundial e OCDE, como o aumento nos níveis e velocidades de fluxos de bens, serviços, mão de obra, tecnologia e capital por todo mundo.

Com efeito, toda essa diversidade de definições faz com que globalização seja uma espécie de termo genérico, podendo vir a significar qualquer coisa, ou coisa alguma. Susan Strange (1996, p. xiii), por exemplo, descreve globalização como "a term which can refer to anything from the Internet to a hamburguer". Mais importante, então, do que buscar uma ou outra definição ou abordagem específica acerca da globalização é entender o conjunto de transformações e novidades que o termo elenca. Nesse sentido, globalização é menos um verbete e mais um glossário composto por vários conceitos, temas e palavras-chaves que, de modo geral, denotam a força do capitalismo como sistema hegemônico global.

Neste glossário das transformações do mundo a partir do capitalismo, palavras como "fluxos", "integração", "privatização", "produção" e "consumo", entre tantas outras, são articuladas para caracterizar a consolidação de processos transfronteiriços supraterritoriais e supranacionais como catalizadores da retração do Estado-nação como unidade política dominante. De fato, uma das transformações mais sublinhadas pelo campo da globalização diz respeito ao Estado-nação, que, parecia, estava com os dias contados.

Autores situados em todo espectro político e teórico, dos mais progressistas e marxistas aos mais liberais e conservadores, argumentavam que o Estado estava em processo de captura por classes capitalistas (Robinson, 2004), tornando-se obsoleto (Scholte, 2005) ou que teria se tornado disfuncional (Ohmae, 1995). Nesse mundo pós-Estado, a política seria privatizada para servir 
aos interesses e agendas de grandes grupos econômicos, que passariam a ocupar e dominar todas as dimensões da sociedade, universalizando os imperativos capitalistas (Woods, 1996). Tudo parecia que seria realmente reordenado e a utopia (ou distopia, a depender da perspectiva) capitalista seguiria firme para sua consolidação planetária.

Diante destas mudanças paradigmáticas produzidas pela globalização, o Estado, até então considerado o foco central dos estudos de segurança, e da disciplina de Relações Internacionais (Rls), também passou a ser questionado pela sua capacidade de prover um dos seus atributos mais basilares: a segurança individual e coletiva (Krause \&Williams, 2018, p. 25; Buzan \& Hansen, 2012, p. 57). A partir da queda do muro de Berlim, proliferou-se o fenômeno dos Estados "frágeis", "falidos" ou "colapsados", marcados, entre outros pontos, pelo alto nível de insegurança pessoal e comunitário (Kaldor, 2012, p. 95-96). Até mesmo nos casos em que estas autoproclamadas fragilidades ou falências não foram claramente denunciadas, questiona-se a capacidade do Estado, enquanto instituição política, de prover segurança contra ameaças e riscos - cada vez mais discursivamente criados à luz de óticas racistas e sexistas. Adicionalmente, diante dos elementos apontados nos parágrafos anteriores, é possível notar uma crescente rearticulação de práticas e processos políticos e sociais impostos pela globalização que redefinem o que é segurança e para quem ela deve ser direcionada.

Eventos como os atentados terroristas às Torres Gêmeas, e a consequente Guerra ao Terror, são exemplos de como dinâmicas associadas à um mundo "hiper-globalizado" produzem novos, criativos e invasivos mecanismos de monitoramento, vigilância, neutralização, acúmulo de informações pessoais e dados sigilosos, além de uma série de elementos relacionados à biométrica $\mathrm{e}$ espaço virtual. Autores das mais variadas vertentes críticas dos Estudos de Segurança Internacional (El) e das Rls produziram reflexões importantes acerca do que a segurança significa e para quem é produzida no contexto tecnológico, financeiro e político do século XXI.

Essa edição especial da Cadernos é um bom indicativo da pluralidade e multiplicidade dos temas e abordagens teóricas que caracterizam o campo de estudos da globalização e da segurança internacional. Ao longo de textos muito bem escritos, os leitores encontrarão temas centrais a tais estudos.

A problematização acerca da força e relevância do Estado nação aparece, por exemplo, nos artigos de Igor Barreto, João Pedro Oliveira, Cristina Farah e 
Antonella Ribeiro, sobre a privatização das forças de segurança diante da fragilidade de Estados e órgãos internacionais, assim como no artigo de Ana Clara Ferreira, que trata do fortalecimento da capacidade de lobby das Companhias Militares e de Segurança Privadas desde a década de 1990.

Inserido numa das principais discussões acerca dos desafios para a segurança internacional do século vigente, o artigo de Ariel Faccioli, acerca da AMERIPOL, apresenta uma excelente discussão sobre a necessidade de mecanismos de governança transgovernamental para o combate efetivo ao crime organizado transfronteiriço. Ariel contribui para a reflexão acerca de como os crimes transnacionais representam uma nova e sui generis ameaça para a segurança privada e pública, "minando as normas morais, sociais e legais" (Jakobi, 2018, p. 487).

Diante de uma possível retração ou disfuncionalidade do Estado-nação e do fortalecimento dos imperativos capitalistas, cidades são frequentemente retratadas nos estudos globalização como novas centralidades fundamentais para a compreensão das dinâmicas políticas, econômicas e sociais contemporâneas. O texto de Cleyton Lima se insere nesse cenário ao buscar compreender o papel que as cidades exercem na integração laboral dos refugiados, observando de perto como essa problemática se desenrola na cidade do Rio de Janeiro.

Outro tema central aos estudos da globalização são as inovações tecnológicas como vetores fundamentais para transformações sociais, políticas e econômicas. Desde a revolução industrial do século XIX, aparatos tecnológicos têm sido cada vez mais centrais para as mais diversas dinâmicas que caracterizam e sustentam a vida no globo, para bem e/ou para mal. Essa centralidade da tecnologia aparece muito bem elaborada no artigo de Maria Eduarda Valente, que trata de como as tecnologias industriais serviram como facilitadoras para estratégias de aniquilação em massa pelos nazistas.

Em meio a multiplicidades de perspectivas, há uma discussão que atravessa todo o campo da globalização: a distinção global/local. Neste número da Cadernos, essa discussão aparece no artigo de Victoria França, que, da perspectiva teórica da "virada prática", analisa relatos e experiências dos assistentes de linguagem na Missão das Nações Unidas para a Estabilização do Haiti (MINUSTAH). Victoria França contribui para a compreensão do quanto esses profissionais são peça chave para a criação de sinergias entre as populações locais e os esforços das Nações Unidas. De igual modo, contribui para uma reflexão crítica sobre os limites e desafios linguísticos que produzem fronteiras 
entre o interno e externo no processo de construção da paz em sociedades afetadas por conflitos armados.

Diante do reordenamento liberal do mundo, as relações de força e disputas de sentido e dos destinos dos povos passaram por grande ressignificação. Princípios e valores liberais se projetaram como dominantes das mais diversas formas, apagando formas de organização social que não necessariamente dialogam ou se encaixam nas molduras do liberalismo político ou econômico. O artigo de Ariane Facci faz uma ótima discussão acerca dessas relações de força ao analisar como o papel das mulheres na Primavera Árabe foi ressignificado para servir a uma narrativa que reduzia a complexidade daquele evento histórico a uma simples busca pela implantação da democracia liberal ocidental no contexto árabe.

Escrevemos essa apresentação no contexto da quarentena devido à pandemia da Covid-19. Diante desse evento realmente global em escala e alcance, é possível perceber que as bases da ordem liberal global pós guerra-fria, que deu origem aos estudos da globalização, parecem estar ruindo. Talvez estejamos entrando em uma nova era histórica, pós-globalização ou até mesmo marcada por uma possível desglobalização. Fato é que proporcional à letalidade e disseminação do novo coronavírus, a guerra comercial entre EUA e China parecem estar avançando para uma possível revitalização da guerra-fria, reintroduzindo, possivelmente, uma ordem regional fechada nos moldes do pós Segunda Guerra Mundial, entre 1945-1989 (Mearsheimer, 2019).

Corremos o risco de sair dessa pandemia em um mundo mais próximo novamente de uma bipolaridade do que de um amplo ordenamento global, ainda que os vestígios liberais se mantenham com muita dificuldade. Claro, dizer isso agora é pura especulação, mas, como demonstra o excelente artigo de Rafaela Romano e Lucas Dantas, o governo de Donald Trump vem se esforçando, desde antes do surgimento do novo coronavírus, para construir uma imagem internacional da China como "ladra" e "trapaceira". Esse esforço de caracterização, argumentam os autores, foi necessário para que o governo Trump legitimasse, interna e internacionalmente, o endurecimento das práticas comerciais em relação à China. Essa reflexão é importante na conjuntura de disputa hegemônica que atravessamos, onde a própria China e também a Rússia, despontam como os principais questionadores da ordem liberal global estadunidense estabelecida a partir da década de 1990. 
Além dos artigos supracitados, os leitores também contam com as resenhas do livro de Perry Anderson "The H-Word: the peripeteia of Hegemony", escrita por João Pedro Toledo, e do livro de Andrew Korybo "Guerras Híbridas: das revoluções coloridas aos golpes", escrita a oito mãos por Magno de Oliveira, Marcelo Mota Júnior, Roberta Bustamante e Yasmim Cavalcante. A primeira publicação, de abril de 2017, é oportuna para a atual conjuntura pois apresenta a genealogia de um dos conceitos mais empregados na Ciência Política e Rls: a hegemonia. Desta forma, ainda que não discorra sobre o cenário geoestratégico vigente, a referida publicação da Editora Verso abre caminhos para nos questionarmos em quais aspectos a hegemonia chinesa em ascensão se assemelha às potências pregressas? Já a segunda publicação, de janeiro de 2018, versa sobre o conceito de guerras híbridas, tática empregada pelos Estados Unidos para a deposição de regimes ao redor do mundo. Diante da possibilidade de retorno à uma ordem cada vez mais confinada às zonas de influência das grandes potências, o livro lançado no Brasil pela Editora Expressão Popular, possibilita uma reflexão sobre a tendência dos conflitos no futuro próximo.

Por fim, gostaríamos de registrar nosso agradecimento à toda equipe editorial da Cadernos de Relações Internacionais pelo incansável trabalho e pela honrosa oportunidade concedida para organizar esta Edição Especial. Desejamos aos leitores uma excelente leitura!

\section{Referências Bibliográficas}

AL-RODHAN, N. R. F.; STOUDMANN, G. Definitions of Globalization: A comprehensive overview and a proposed definition. Geneva Centre for Security Policy, Geneva, 19 jun. 2006.

BUZAN, Barry; HANSEN, Lene. A Evolução dos Estudos de Segurança Internacional. São Paulo: Editora UNESP, 2012.

JAKOBI, Anja P. The Crime Scene: What Lessons for International Security? In: GHECIU, Alexandra; WOHLFORTH, William C. (Eds.). The Oxford Handbook of International Security. Oxford: Oxford University Press:2018, p. 487-501.

KRAUSE, Keith; WILLIAMS, Michael C. Security and "Security Studies": Conceptual Evolution and Historical Transformation. In: GHECIU, Alexandra; WOHLFORTH, William C. (Eds.). The Oxford Handbook of International Security. Oxford: Oxford University Press. 2018, p. 14-28.

MEARSHEIMER, John J. Bound to Fail - The Rise and Fall of the Liberal International Order. International Security, v. 43, n. 4, p. 7-50, 2019.

MOSS KANTER, R. World Class: Thriving Locally in the Global Economy. Nova York: Simon and Schuster, 1995. 
NEERAJ, J. Globalisation or Recolonisation. Pune: Elgar, 2001.

OHMAE, K. The End of the Nation-State: the Rise of Regional Economies. Nova York: Simon and Schuster Inc., 1995. 214 p.

SCHOLTE, J. A. Globalization: a critical introduction. London: Palgrave , 2005.

STRANGE, S. The Retreat of the State. Cambridge: Cambridge University Press, 1996.

ROBINSON, W. I. A Theory of Global Capitalism: production, class, and state in a transnational world. Baltimore: The Johns Hopkins University Press, 2004.

WOODS, E. M. Modernity, Postmodernity, or Capitalism? Monthly Review, v. 48, n. 3, p. 21, Jul/Aug 1996. 